\title{
Non-operative management of appendicitis in children
}

Nigel J Hall $\mathrm{PhD}^{1,2}$, Simon Eaton $\mathrm{PhD}^{3}$

Affiliations:

1. University Surgery Unit, Faculty of Medicine, University of Southampton, Southampton, UK

2. Department of Paediatric Surgery and Urology, Southampton Children's Hospital, Southampton, UK

3. UCL Great Ormond Street Institute of Child Health, London, UK

Funding source: No funding was secured for this study

Financial disclosure: Neither of the authors have any financial relationships relevant to this article to disclose.

Conflict of Interest: The authors have no conflicts of interest to disclose.

Contributorship statement: Simon Eaton and Nigel Hall contributed equally to the writing of this manuscript, including drafting of the initial manuscript and its subsequent revision.

\section{Corresponding author}

Nigel J Hall

Faculty of Medicine, University of Southampton, Mailpoint 816, Southampton General Hospital, Tremona Road, Southampton SO16 6YD UK

Tel: 0238120 6146; Email n.j.hall@soton.ac.uk 


\section{ABSTRACT}

Whilst appendicectomy has been considered the mainstay of treatment for children with acute appendicitis for many decades there has been a great deal of recent interest in non-operative treatment (NOT) with antibiotics alone. Initial results suggest that many children with appendicitis can indeed be safely treated with NOT and can be spared the surgeon's knife. Many as yet unanswered questions remain however before NOT can be considered a realistic and reliable alternative to the surgery. This review summaries current knowledge and understanding of the role of NOT in children with appendicitis and outlines and discusses the outstanding knowledge gaps. 


\section{Introduction}

Acute appendicitis affects between 7 and $8 \%$ of the worldwide population at some point in their lifetime and as such is one of the most common general surgical emergencies(1).

Appendicitis is of particular relevance to children since the incidence peaks in the second decade of life $(1,2)$. Overall, acute appendicitis is diagnosed in $1 \%$ to $8 \%$ of children presenting to the emergency department with acute abdominal pain (3-5). Diagnosis is either clinical, or supported by diagnostic imaging (usually ultrasound or computed tomography scan).

Over 130 years ago Fitz reported appendicectomy for appendicitis(6), and this operation has become the mainstay of treatment of acute appendicitis. Of note this was several decades prior to the discovery and widespread availability of modern antibiotics. However, in recent years the dogma that surgery is required has been challenged and there is growing literature to suggest that antibiotics without surgery may be an effective treatment for acute appendicitis in adults (7-9) and more recently in children (10-12). This non-operative treatment (NOT) of acute appendicitis in children remains controversial and unproven at present due to a lack of randomised controlled trials and other large prospective evaluations(13).

In this article we focus primarily on the treatment of children with uncomplicated acute appendicitis (UAA). UAA may be defined as acute appendicitis without perforation, development of peri-appendicular abscess or an appendix mass. This form of appendicitis is receiving greatest attention currently in the context of NOT. Of note, the distinction between UAA and more advanced forms of appendicitis may be difficult to make with certainty on either clinical or radiological grounds and the definitive diagnosis of acute uncomplicated appendicitis may only be apparent on macroscopic and/or histological appearance of the appendix at appendicectomy. We review the role of NOT of acute appendicitis in children based on the existing literature, highlight current gaps in the evidence base and identify key areas for future knowledge generation as we strive to determine the role of NOT when compared to surgery for this common illness.

\section{Historical context}

Although appendicectomy is the mainstay of treatment for acute appendicitis in the developed world, the concept of using antibiotics without surgery to treat appendicitis is not a new one. In 1956 Coldrey challenged the dogma that all patients with acute appendicitis required appendicectomy and reported successful NOT in 137 cases with low morbidity and low mortality(14). A report in 1977 of over 400 cases of acute appendicitis claimed high success and low recurrence (7\%) with a combination of antibiotics and traditional Chinese medicines(15). In environments without access to surgical care (e.g. submariners, merchant navy) appendicitis has been treated non-operatively with antibiotics for many years, with well-documented evidence of high success rates $(16,17)$. Despite this, throughout recent decades, the majority of adults and children with acute appendicitis have been treated surgically, with an appendicectomy.

An anomalous exception to this has been the child presenting with an advanced form of appendicitis known as an appendix mass. An appendix mass is an inflammatory mass centred on the appendix and usually formed by loops of intestine and omentum which become adherent to the appendix and inflamed. There may be a small abscess within the mass. Up to $9 \%$ of children may present with an appendix mass (18). Cases of appendix mass are often treated with antibiotics alone since the risk of damage to these adjacent structures during dissection of the inflammatory mass is high. The majority of cases of appendix mass respond well to intravenous 
and subsequently oral antibiotics with resolution of symptoms (18). Some children with successful treatment of appendix mass are electively operated later by interval appendectomy, although this is by no means universal, and only $12 \%$ of children who have had successful nonoperative treatment of appendix mass have a subsequent recurrence of acute appendicitis within one year (19). Since most surgeons have experience of treating children with appendicitis non-operatively, expertise with NOT of acute appendicitis does currently exist and it is not, therefore, a completely new concept.

In the mid-1990s clinicians began to evaluate the role of NOT for UAA as primary therapy in developed healthcare settings (20). Since then a number of studies have investigated the relative performance of NOT as primary therapy initially in adults with UAA $(7,9,21,22)$. In adults it is recognised that a high proportion of cases can be successfully treated without an operation (23). However the evidence is not yet strong enough to support a widespread shift in treatment approach to this disease and for the time being appendicectomy remains commonplace (23). Further large scale evaluations of non-operative treatment of uncomplicated appendicitis in adults, particularly in comparison to appendicectomy are warranted and ongoing (24). Some of the recent trials also include economic analyses which suggested that costs were significantly lower in patients treated with NOT (25).

\section{NOT for uncomplicated acute appendicitis in children}

Investigation of NOT for the management of UAA in children has lagged behind that in adults to some extent but is currently gaining momentum rapidly. A number of studies have to date reported outcomes of children with UAA treated with NOT pathways either in isolation or in comparison to children who have undergone surgery $(10,12,26-33)$. To date there has been just one prospective RCT (a pilot RCT) reported of this comparative evaluation (28). Existing studies have been of children who were initially selected based on clinical and/or laboratory test parameters (e.g. short duration of history, no faecolith on imaging, moderately raised white blood cell count) $(30,34)$. More recently NOT has been evaluated in a wider spectrum of children who are less selected (35). Perhaps unsurprisingly NOT failure rates appear higher in less highly selected patient populations. Of note however, these studies are not RCTs so it is impossible to be sure of the comparative outcomes between NOT and appendicectomy in comparable populations.

Several systematic reviews and meta-analyses have been undertaken summarising the collective evidence to date (36-39). Importantly these reports have demonstrated that NOT pathways, which include close monitoring to ensure that children treated without surgery are improving satisfactorily, are safe. Furthermore NOT appears effective as initial treatment in the vast majority of cases. When considering all reports of NOT (comparative and non-comparative) Georgiou reported success rates of NOT (defined as discharge home from hospital without appendicectomy during initial hospital admission) in excess of $97 \%$ (37). In the most recent systematic review (39) reporting NOT for UAA in children, success rate of NOT was $89 \%$ or higher in 14 of the 15 included studies but notably only $58 \%$ in one report (40). What is less clear however, due primarily to the absence of well-designed RCTs, is the relative efficacy of NOT when compared to appendicectomy. A number of groups worldwide are currently in the process of performing the systematic evaluations that are necessary to inform treatment choices in the form of RCTs (41-43) whilst other groups are using alternate prospective methodology (10) 
In addition to clinical outcomes there is much interest in the relative costs of NOT and appendicectomy for children using both real patient data (44) and financial modelling (45). It is evident that cost effectiveness will be an important consideration when analysing and interpreting the comparative effectiveness research.

\section{NOT for perforated appendicitis in children}

A varying proportion of children but up to $50 \%$ in some series(46) present with perforated appendicitis. In similarity to uncomplicated appendicitis, the treatment of perforated appendicitis has traditionally been appendicectomy but it is now recognised that cases of perforated acute appendicitis can also be treated safely and effectively with antibiotics alone, or in cases of intra-abdominal abscess with antibiotics and percutaneous image guided abscess drainage.

Two RCTs have evaluated NOT and appendicectomy for perforated appendicitis in children (47, 48) and a recent review evaluated patient-level data from these two RCTs (49). Current data support emergency appendicectomy in children with perforated appendicitis in whom no intraabdominal abscess is present but in the presence of an abscess at presentation, comparable outcomes can be achieved with either NOT or surgery (49).

\section{Improving the evidence base - what we need to know}

If there is a future for NOT in children, then there are a number of knowledge gaps to be filled before appropriate evidence-based decisions can be taken by surgeons, commissioners, parents and children. These include:

- Are there any disadvantages to removing the appendix?

- If an operation is not performed, what is the likelihood of the appendix perforating or other serious complications occurring, either during the first admission or subsequently

- If the child has successful resolution of symptoms following NOT, what is the likelihood of appendicitis recurring, either in the short or long-term?

- Is it possible to identify those children who will respond successfully to NOT, or those that will not respond and potentially perforate if not operated?

- What will be the psychological impact of not having the appendix removed- will some parents and children regard the remaining appendix as a 'ticking time bomb' that might affect their future activities (for example, taking holidays, or later working in, medicalresource-poor settings)?

- Is NOT for appendicitis cost-effective? Although it might be assumed that not operating makes treatment cheaper, children are usually discharged from hospital quickly following appendectomy, whereas children undergoing NOT may stay in hospital longer, so that this assumption may not be true.

- What if the diagnosis is not appendicitis?

Surprisingly, for a common disease, we do not know the answer to two more fundamental questions which underpin several of those questions above. These are: what is the biological function of the appendix, and what is the pathogenesis of acute appendicitis? 
Darwin and many others have regarded the appendix as useless, but recent evidence suggests that the appendix has evolved at least 32 different times during mammalian evolution(50), and that the function of the appendix during human evolution is to act as a reservoir of beneficial microbiota to rapidly recolonise the intestine following diarrhoeal infections(50). The pathogenesis of acute appendicitis involves an interaction between the microbiota, the immune response, and blockage of the appendix, by a faecolith for example, but we are still far from a complete understanding of the pathogenesis(51). Might there be an advantage to leaving the appendix in place? Complications following appendectomy are rare, and although there are diseases when the appendix is useful as a surgical conduit, these are even more rare and cannot justify non-removal of the appendix. By removal of the appendix, however, we are removing an immune organ and potentially a reservoir of beneficial microbiota. This may predispose to subsequent development of other pathologies, such as recurrent Clostridium difficile infection, (52) Crohn's disease (53) and colorectal cancer (54) although this is a controversial area and it is difficult to dissect appendicitis from appendectomy, and to control for diagnostic uncertainty.

As the pathogenesis of acute appendicitis is not completely elucidated, the progression of disease from uncomplicated appendicitis to complicated appendicitis, with perforation and peritonitis is uncertain. Whilst it has traditionally been assumed that uncomplicated appendicitis will progress to complicated appendicitis without appropriate treatment, there is increasing evidence that this may not be the case. It is possible that there are instead two (or perhaps more) distinct pathological entities and that some cases of appendicitis are 'destined' to become complicated whilst others are not (55). This is supported by a number of studies that demonstrate no detrimental effect related to in-hospital delays after a diagnosis of appendicitis whilst waiting for appendicectomy $(56,57)$. It may be that uncomplicated and complicated appendicitis are effectively two separate entities.

In an ideal world we would be able to select children who could be predicted to respond to NOT and treat them without surgery, whilst reserving surgery for the remainder. At present we are unable to make this prediction. Although a number of scoring systems exist to assist with diagnosis of acute appendicitis (e.g. Alvarado score and the Paediatric Appendicitis Score (58)), none can currently inform us which children are likely to respond to NOT, which children are not going to respond to NOT, and which children may be at risk of perforation. Only when we have large datasets from the prospective studies described above might we be able to develop these systems.

At the same time as generating these large datasets it is imperative that qualitative work regarding the impact of NOT on children and their families, and full cost-effectiveness and costutility evaluations are undertaken so we can understand fully the wider implications of NOT beyond the immediate clinical outcomes.

Finally we must consider diagnostic certainty if we are to pursue NOT in large number of children. Is there a chance that a child presumed to have appendicitis is treated 'successfully' with NOT but actually has a more sinister diagnosis? The most important underlying diagnosis is likely that of a carcinoid tumour. Previous studies of children who present initially with an appendix mass and treated initially with NOT found an incidence of carcinoid tumour of $<1 \%$ $(59,60)$ which is within the range of overall incidence in the general population of developing a 
carcinoid tumour at any site (61). With this and other potential diagnoses (e.g. inflammatory bowel disease) in mind it would seem prudent to restrict NOT to the first episode of UAA, proceeding with further investigation, and possibly appendicectomy, for recurrence or residual symptoms.

\section{Challenges of designing RCTs}

RCTs in surgery are always challenging, particularly when the treatments being compared are markedly different. NOT and surgery represent conceptually very different treatment strategies for both surgeons and parents. This, combined with the fact that RCTs need to recruit children in an emergency setting mean that recruitment is likely to be challenging. Whilst these challenges may be surmountable, particularly with the use of qualitative research techniques of proven efficacy $(43,62)$, there remain methodological challenges, primarily related to selecting an appropriate primary outcome.

RCTs comparing NOT and appendicectomy are likely to be designed to demonstrate either superiority of one treatment over the other or non-inferiority of NOT compared to appendicectomy. A statistical comparison must be made between the incidence of a common primary outcome in each treatment group. This is precisely where the problem arises since the outcomes of primary interest in each group are not identical. The main outcome of interest in individuals allocated to appendicectomy is likely complications of surgery. Many also believe that negative appendicectomy (i.e. removal of an appendix in a child who did not actually have appendicitis) is equally important since this would represent surgery that had been performed unnecessarily (41). The negative appendicectomy rate in in the UK is approximately $10 \%$ for children treated in specialist paediatric surgical centres and $24 \%$ for children treated by adult general surgeons (63) but in some centres in which all children have a radiological diagnosis (ultrasound with CT for equivocal findings) may be as low as 1-2\%. Inclusion of negative appendicectomy in a composite primary outcome for a RCT will likely have significant impact on the 'success rate' of a surgical treatment arm and thence overall sample size. Similarly, the negative appendectomy rate in centres involved in an RCT will have a strong influence on sample size. In children treated with NOT, failure of NOT to adequately treat appendicitis is likely the most important outcome but another important factor to consider is need for later appendicectomy for recurrence. If a high proportion of children treated with NOT develop recurrent appendicitis, there is little benefit to an initial course of NOT. Bearing these factors in mind, what then should be the primary outcome for future RCTs? How should 'failure of treatment' be defined - what might seem like success to a surgeon might be deemed a failure to a child or their parent.

Current examples of primary outcomes in RCTs completed or in progress are all composite primary outcomes, including various combinations of those individual outcomes detailed above $(28,41,42)$. It remains unknown however, what surgeons, parents and other stakeholders believe should be measured and reported in RCTs of this nature. Work we are currently undertaking to develop a core outcome set for the treatment of children with UAA will hopefully enlighten this debate and inform our future work $(43,64)$.

\section{Conclusion}

Current interest in NOT for acute appendicitis in children is at a high level and efforts are in place not only to improve the evidence base but importantly to define the precise role of NOT for children with appendicitis. Until this work has been completed and the evidence base 
improved we would caution against any change in current practice. In particular we would not encourage a diagnosis of appendicitis to be made without thorough assessment by a surgeon, nor for NOT to be instigated outside the closely monitored environment of a research study, ideally a RCT(65). We also caution against 'therapeutic creep' towards treatment of abdominal pain (not appendicitis) with courses of antibiotics.

If NOT proves to be effective then the treatment of acute appendicitis may be revolutionised. More likely, we suspect, is that the data will suggest some children can be successfully treated without surgery. The challenge will be to define this population precisely so that NOT can be offered as a realistic alternative to them whilst reserving surgery for those who really need it.

\section{ACKNOWLEDGEMENTS}

NJH is supported by the Southampton NIHR Biomedical Research Centre in nutrition. SE is supported by Great Ormond Street Hospital NIHR Biomedical Research Centre and by Great Ormond Street Children's Charity. 
1. Addiss DG, Shaffer N, Fowler BS, et al. The epidemiology of appendicitis and appendectomy in the United States. Am J Epidemiol. 1990;132:910-25

2. Al-Omran M, Mamdani M, McLeod RS. Epidemiologic features of acute appendicitis in Ontario, Canada. Can J Surg. 2003;46:263-8

3. Reynolds SL, Jaffe DM. Children with abdominal pain: evaluation in the pediatric emergency department. Pediatr Emerg Care. 1990;6:8-12

4. Reynolds SL, Jaffe DM. Diagnosing abdominal pain in a pediatric emergency department. Pediatr Emerg Care. 1992;8:126-8

5. Scholer SJ, Pituch K, Orr DP, et al. Clinical outcomes of children with acute abdominal pain. Pediatrics. 1996;98:680-5

6. Fitz RH. Perforating inflammation of the vermiform appendix with special reference to its early diagnosis and treatment. Trans Assoc Am Physicians. 1886;1:107-44

7. Styrud J, Eriksson S, Nilsson I, et al. Appendectomy versus antibiotic treatment in acute appendicitis. a prospective multicenter randomized controlled trial. World J Surg. 2006;30:1033-7 doi: 10.1007/s00268-005-0304-6 [doi]

8. Svensson JF, Hall NJ, Eaton S, et al. A review of conservative treatment of acute appendicitis. Eur J Pediatr Surg. 2012;22:185-94 doi: 10.1055/s-0032-1320014 [doi]

9. Hansson J, Korner U, Khorram-Manesh A, et al. Randomized clinical trial of antibiotic therapy versus appendicectomy as primary treatment of acute appendicitis in unselected patients. Br J Surg. 2009;96:473-81 doi: 10.1002/bjs.6482 [doi]

10. Minneci PC, Mahida JB, Lodwick DL, et al. Effectiveness of Patient Choice in Nonoperative vs Surgical Management of Pediatric Uncomplicated Acute Appendicitis. JAMA Surg. 2015:1-8 doi: 10.1001/jamasurg.2015.4534

11. Svensson JF, Patkova B, Almstrom M, et al. Nonoperative Treatment With Antibiotics Versus Surgery for Acute Nonperforated Appendicitis in Children: A Pilot Randomized Controlled Trial. Ann Surg. 2014; doi: 10.1097/SLA.0000000000000835 [doi]

12. Armstrong J, Merritt N, Jones S, et al. Non-operative management of early, acute appendicitis in children: is it safe and effective? J Pediatr Surg. 2014;49:782-5 doi: S00223468(14)00171-7 [pii];10.1016/j.jpedsurg.2014.02.071 [doi]

13. Wilms IM, de Hoog DE, de Visser DC, et al. Appendectomy versus antibiotic treatment for acute appendicitis. Cochrane Database Syst Rev. 2011:CD008359 doi: 10.1002/14651858.CD008359.pub2 [doi]

14. Coldrey E. Treatment of Acute Appendicitis. Br Med J. 1956;2:1458-61

15. Combined traditional Chinese and western medicine in acute appendicitis. Chinese medical journal. 1977;3:266-9

16. BOWERS WF, HUGHES CW, BONILLA KB. The treatment of acute appendicitis under suboptimal conditions. U S Armed Forces Med J. 1958;9:1545-57

17. Campbell MR, Johnston SL, III, Marshburn T, et al. Nonoperative treatment of suspected appendicitis in remote medical care environments: implications for future spaceflight medical care. J Am Coll Surg. 2004;198:822-30 doi: 10.1016/j.jamcollsurg.2004.01.009 [doi];S1072-7515(04)00040-7 [pii]

18. Andersson RE, Petzold MG. Nonsurgical treatment of appendiceal abscess or phlegmon: a systematic review and meta-analysis. Ann Surg. 2007;246:741-8

19. Hall NJ, Eaton S, Stanton MP, et al. Active observation versus interval appendicectomy after successful non-operative treatment of an appendix mass in children 
(CHINA study): an open-label, randomised controlled trial. The lancet Gastroenterology \& hepatology. 2017;2:253-60 doi: 10.1016/s2468-1253(16)30243-6

20. Eriksson S, Granstrom L. Randomized controlled trial of appendicectomy versus antibiotic therapy for acute appendicitis. Br J Surg. 1995;82:166-9

21. Vons C, Barry C, Maitre S, et al. Amoxicillin plus clavulanic acid versus appendicectomy for treatment of acute uncomplicated appendicitis: an open-label, noninferiority, randomised controlled trial. Lancet. 2011;377:1573-9 doi: S0140-

6736(11)60410-8 [pii];10.1016/S0140-6736(11)60410-8 [doi]

22. Salminen P, Paajanen H, Rautio T, et al. Antibiotic Therapy vs Appendectomy for Treatment of Uncomplicated Acute Appendicitis: The APPAC Randomized Clinical Trial. JAMA. 2015;313:2340-8 doi: 2320315 [pii];10.1001/jama.2015.6154 [doi]

23. Rollins KE, Varadhan KK, Neal KR, et al. Antibiotics Versus Appendicectomy for the Treatment of Uncomplicated Acute Appendicitis: An Updated Meta-Analysis of Randomised Controlled Trials. World J Surg. 2016; doi: 10.1007/s00268-016-3561-7

24. The Comparison of Outcomes of Antibiotic Drugs and Appendectomy (CODA) Trial. https://clinicaltrials.gov/ct2/show/NCT02800785 (accessed 24/07/2017).

25. Sippola S, Grönroos J, Tuominen R, et al. Economic evaluation of antibiotic therapy versus appendicectomy for the treatment of uncomplicated acute appendicitis from the APPAC randomized clinical trial. British Journal of Surgery.n/a-n/a doi: 10.1002/bjs.10575 26. Tanaka Y, Uchida H, Kawashima H, et al. Long-term outcomes of operative versus nonoperative treatment for uncomplicated appendicitis. J Pediatr Surg. 2015;50:1893-7 doi: 10.1016/j.jpedsurg.2015.07.008

27. Steiner Z, Buklan G, Stackievicz R, et al. A role for conservative antibiotic treatment in early appendicitis in children. J Pediatr Surg. 2015; doi: S0022-3468(15)00278-X [pii];10.1016/j.jpedsurg.2015.04.008 [doi]

28. Svensson JF, Patkova B, Almstrom M, et al. Nonoperative treatment with antibiotics versus surgery for acute nonperforated appendicitis in children: a pilot randomized controlled trial. Ann Surg. 2015;261:67-71 doi: 10.1097/SLA.0000000000000835 29. Hartwich J, Luks FI, Watson-Smith D, et al. Nonoperative treatment of acute appendicitis in children: A feasibility study. J Pediatr Surg. 2016;51:111-6 doi: 10.1016/j.jpedsurg.2015.10.024

30. Kaneko K, Tsuda M. Ultrasound-based decision making in the treatment of acute appendicitis in children. J Pediatr Surg. 2004;39:1316-20

31. Abes M, Petik B, Kazil S. Nonoperative treatment of acute appendicitis in children.J Pediatr Surg. 2007;42:1439-42 doi: S0022-3468(07)00190-X

[pii];10.1016/j.jpedsurg.2007.03.049 [doi]

32. Gorter RR, van der Lee JH, Cense HA, et al. Initial antibiotic treatment for acute simple appendicitis in children is safe: Short-term results from a multicenter, prospective cohort study. Surgery. 2015;157:916-23 doi: S0039-6060(15)00020-3

[pii];10.1016/j.surg.2015.01.008 [doi]

33. Koike Y, Uchida K, Matsushita K, et al. Intraluminal appendiceal fluid is a predictive factor for recurrent appendicitis after initial successful non-operative management of uncomplicated appendicitis in pediatric patients. J Pediatr Surg. 2014;49:1116-21 doi: 10.1016/j.jpedsurg.2014.01.003

34. Minneci PC, Sulkowski JP, Nacion KM, et al. Feasibility of a nonoperative management strategy for uncomplicated acute appendicitis in children. J Am Coll Surg. 2014;219:272-9 doi: S1072-7515(14)00325-1 [pii];10.1016/j.jamcollsurg.2014.02.031 [doi]

35. Bachur RG, Lipsett SC, Monuteaux MC. Outcomes of Nonoperative Management of Uncomplicated Appendicitis. Pediatrics. 2017;140 doi: 10.1542/peds.2017-0048 
36. Gorter RR, The SML, Gorter-Stam MAW, et al. Systematic review of nonoperative versus operative treatment of uncomplicated appendicitis. J Pediatr Surg. 2017; doi: 10.1016/j.jpedsurg.2017.04.005

37. Georgiou R, Eaton S, Stanton MP, et al. Efficacy and Safety of Nonoperative Treatment for Acute Appendicitis: A Meta-analysis. Pediatrics. 2017;139 doi: 10.1542/peds.2016-3003

38. Huang L, Yin Y, Yang L, et al. Comparison of Antibiotic Therapy and Appendectomy for Acute Uncomplicated Appendicitis in Children: A Meta-analysis. JAMA Pediatr. 2017;171:426-34 doi: 10.1001/jamapediatrics.2017.0057

39. Xu J, Adams S, Liu YC, et al. Nonoperative management in children with early acute appendicitis: A systematic review. J Pediatr Surg. 2017; doi:

10.1016/j.jpedsurg.2017.05.003

40. Caruso AM, Pane A, Garau R, et al. Acute appendicitis in children: not only surgical treatment. J Pediatr Surg. 2017;52:444-8 doi: 10.1016/j.jpedsurg.2016.08.007

41. Hall NJ, Eaton S, Abbo O, et al. Appendectomy versus non-operative treatment for acute uncomplicated appendicitis in children: study protocol for a multicentre, open-label, non-inferiority, randomised controlled trial. BMJ Paediatrics Open. 2017;1 doi:

10.1136/bmjpo-2017-000028

42. Xu J, Liu YC, Adams S, et al. Acute uncomplicated appendicitis study: rationale and protocol for a multicentre, prospective randomised controlled non-inferiority study to evaluate the safety and effectiveness of non-operative management in children with acute uncomplicated appendicitis. BMJ Open. 2016;6:e013299 doi: 10.1136/bmjopen-2016013299

43. Non operative treatment of children with appendicitis vs appendectomy - A feasibility study. http://www.isrctn.com/ISRCTN15830435 (accessed 24/07/2017). 44. Mudri M, Coriolano K, Butter A. Cost analysis of nonoperative management of acute appendicitis in children. J Pediatr Surg. 2017;52:791-4 doi: 10.1016/j.jpedsurg.2017.01.050 45. Wu JX, Sacks GD, Dawes AJ, et al. The cost-effectiveness of nonoperative management versus laparoscopic appendectomy for the treatment of acute, uncomplicated appendicitis in children. J Pediatr Surg. 2017;52:1135-40 doi: 10.1016/j.jpedsurg.2016.10.009

46. Rentea RM, St. Peter SD. Contemporary Management of Appendicitis in Children. Advances in Pediatrics. 2017;64:225-51 doi: http://dx.doi.org/10.1016/i.yapd.2017.03.008

47. Blakely ML, Williams R, Dassinger MS, et al. Early vs interval appendectomy for children with perforated appendicitis. Arch Surg. 2011;146:660-5 doi: archsurg.2011.6 [pii];10.1001/archsurg.2011.6 [doi]

48. St Peter SD, Aguayo P, Fraser JD, et al. Initial laparoscopic appendectomy versus initial nonoperative management and interval appendectomy for perforated appendicitis with abscess: a prospective, randomized trial. J Pediatr Surg. 2010;45:236-40 doi: S00223468(09)00821-5 [pii];10.1016/j.jpedsurg.2009.10.039 [doi]

49. Duggan EM, Marshall AP, Weaver KL, et al. A systematic review and individual patient data meta-analysis of published randomized clinical trials comparing early versus interval appendectomy for children with perforated appendicitis. Pediatric Surgery International. 2016;32:649-55 doi: 10.1007/s00383-016-3897-y

50. Smith HF, Parker W, Kotze SH, et al. Morphological evolution of the mammalian cecum and cecal appendix. Cr Palevol. 2017;16:39-57 doi: 10.1016/j.apv.2016.06.001 51. Soreide K. The research conundrum of acute appendicitis. British Journal of Surgery. 2015;102:1151-2 doi: 10.1002/bjs.9890 
52. Yong FA, Alvarado AM, Wang HP, et al. Appendectomy: a risk factor for colectomy in patients with Clostridium difficile. American Journal of Surgery. 2015;209:532-5 doi:

10.1016/j.amjsurg.2014.12.001

53. Kaplan GG, Jackson T, Sands BE, et al. The risk of developing Crohn's disease after an appendectomy: a meta-analysis. Am J Gastroenterol. 2008;103:2925-31 doi:

10.1111/j.1572-0241.2008.02118.x

54. Wu SC, Chen WTL, Muo CH, et al. Association between Appendectomy and

Subsequent Colorectal Cancer Development: An Asian Population Study. Plos One. 2015;10 doi: 10.1371/journal.pone.0118411

55. Bhangu A, Soreide K, Di Saverio S, et al. Acute appendicitis: modern understanding of pathogenesis, diagnosis, and management. Lancet. 2015;386:1278-87

56. Bhangu A. Safety of short, in-hospital delays before surgery for acute appendicitis: multicentre cohort study, systematic review, and meta-analysis. Ann Surg. 2014;259:894903 doi: 10.1097/SLA.0000000000000492 [doi]

57. Almstrom M, Svensson JF, Patkova B, et al. In-hospital Surgical Delay Does Not Increase the Risk for Perforated Appendicitis in Children: A Single-center Retrospective Cohort Study. Ann Surg. 2016; doi: 10.1097/SLA.0000000000001694

58. Samuel M. Pediatric appendicitis score. Journal of Pediatric Surgery. 2002;37:877-81 doi: http://dx.doi.org/10.1053/jpsu.2002.32893

59. Hall NJ, Jones CE, Eaton S, et al. Is interval appendicectomy justified after successful nonoperative treatment of an appendix mass in children? A systematic review.J Pediatr Surg. 2011;46:767-71 doi: 10.1016/j.jpedsurg.2011.01.019

60. Hall NJ, Eaton S, Stanton MP, et al. Active observation versus interval appendicectomy after successful non-operative treatment of an appendix mass in children (CHINA study): an open-label, randomised controlled trial. The Lancet Gastroenterology \& Hepatology. 2017; doi: 10.1016/S2468-1253(16)30243-6

61. Hodgson HJ. Carcinoid tumours and the carcinoid syndrome. In: Bonchier IAA, R.N.; Hodgson,H.J.; Keighley,M.R.O., ed. Gastroenterology: clinical science and practice. London: WB Saunders 1992:643-58.

62. Donovan J, Mills N, Smith M, et al. Quality improvement report: Improving design and conduct of randomised trials by embedding them in qualitative research: ProtecT (prostate testing for cancer and treatment) study. Commentary: presenting unbiased information to patients can be difficult. BMJ. 2002;325:766-70

63. Tiboni S, Bhangu A, Hall NJ. Outcome of appendicectomy in children performed in paediatric surgery units compared with general surgery units. Br J Surg. 2014;101:707-14 doi: $10.1002 /$ bjs. 9455 [doi]

64. Sherratt F. Development of a core outcome set to determine the overall treatment success of acute uncomplicated appendicitis in children: a study protocol. BMJ Paediatrics Open. 2017;

65. Svensson JF, Patkova B, Almstrom M, et al. Design of Studies for Antibiotic Treatment of Acute Appendicitis in Children: In Support of RCTs. Ann Surg. 2017;266:e6-e7 doi: 10.1097/SLA.0000000000001291 